\title{
Isolation and identification of inulooligosaccharides resulting from inulin hydrolysis
}

\author{
Sébastien N. Ronkart ${ }^{a, b, *}$, Christophe S. Blecker ${ }^{a}$, Hélène Fourmanoir ${ }^{a, b}$, \\ Christian Fougnies ${ }^{c}$, Claude Deroanne ${ }^{a}$, Jean-Claude Van Herck ${ }^{c}$, Michel Paquot ${ }^{b}$ \\ a Department of Food Technology, Gembloux Agricultural University, Passage des Déportés 2, B-5030 Gembloux, Belgium \\ ${ }^{\mathrm{b}}$ Department of Industrial Biological Chemistry, Gembloux Agricultural University, Passage des Déportés 2, B-5030 Gembloux, Belgium \\ c Cosucra Groupe Warcoing S.A., Rue de la Sucrerie 1, B-7740 Warcoing, Belgium
}

\section{A R T I C L E I N F O}

\section{Article history:}

Received 25 June 2007

Accepted 31 July 2007

Published on line 6 August 2007

Keywords:

Inulin

Hydrolysis

Globe artichoke

Endo-inulinase

Purification

Elution profile

\begin{abstract}
A B S T R A C T
In this study, inulooligosaccharides $\left(F_{n}\right.$-type inulin) resulting from the endo-inulinase hydrolysis of globe artichoke inulin were purified and characterized. The aim was to produce $\mathrm{F}_{n}$ oligomer standards with the intention of identifying them in the complex inulin chromatogram. Inulin was extracted from globe artichoke and presented a high average degree of polymerization (DP) of about 80 as determined by high-performance anion exchange chromatography coupled with pulsed amperometric detection (HPAEC-PAD). This inulin was hydrolyzed by a commercial endo-inulinase yielding a product with a very high $\mathrm{F}_{n} / \mathrm{GF}_{n}$ molecule ratio, thus limiting the interference of $\mathrm{GF}_{n}$ during the purification process. Highperformance size exclusion chromatography was used to individually isolate and collect each retention peak corresponding to a specific oligomer. The purity of these fractions was checked by HPAEC-PAD and showed that relatively pure molecules were produced. Electrospray ionization mass spectrometry allowed the molecular weight determination of these purified oligomers and ascertained their DP as $F_{2}, F_{3}$ and $F_{4}$. These $F_{2-4}$ standards were used with glucose, fructose, sucrose and $\mathrm{GF}_{2-4}$ (commercially available) to spike commercial oligofructose products in order to determine the elution profile in the HPAEC-PAD chromatogram.
\end{abstract}

(c) 2007 Elsevier B.V. All rights reserved.

\section{Introduction}

Inulin is a natural storage carbohydrate mainly found in plants from the Asteraceae family. It is not a simple molecule, but a mixture of oligo- and/or polysaccharides composed of fructose unit chains (linked by $\beta-(2 \rightarrow 1)$ $D$-fructosyl-fructose bonds) of various length, terminated generally by a single glucose unit (linked by an $\alpha$-Dglucopyranosoyl bond). Inulins with a terminal glucose unit are called as $\alpha$-D-glucopyranosyl-[ $\beta$-D-fructofuranosyl $]_{n-1}$ -
D-fructofuranoside (or fructooligosaccharide), while those only constituted by fructose are $\beta$-D-fructopyranosyl-[ $\alpha-D$ fructofuranosyl $]_{n-1}$-D-fructofuranoside (or inulooligosaccharide) [1]. So, the general formula may be depicted as $\mathrm{GF}_{n}$ or $F_{n}$, with $G$ as glucose and $F$ as fructose, and $n$ characterizing the total number of units (Fig. 1).

Composition depends on the plant source, harvesting date but also on extraction and post-extraction processes [2,3]. As the use of inulin and derivatives is in constant increase in the food industry, essentially as a nutritional food ingredient,

* Corresponding author at: Department of Industrial Biological Chemistry, Gembloux Agricultural University, Passage des Déportés 2, B-5030 Gembloux, Belgium. Tel.: +32 81 622232; fax: +32 81622231.

E-mail address: ronkart.s@fsagx.ac.be (S.N. Ronkart). 


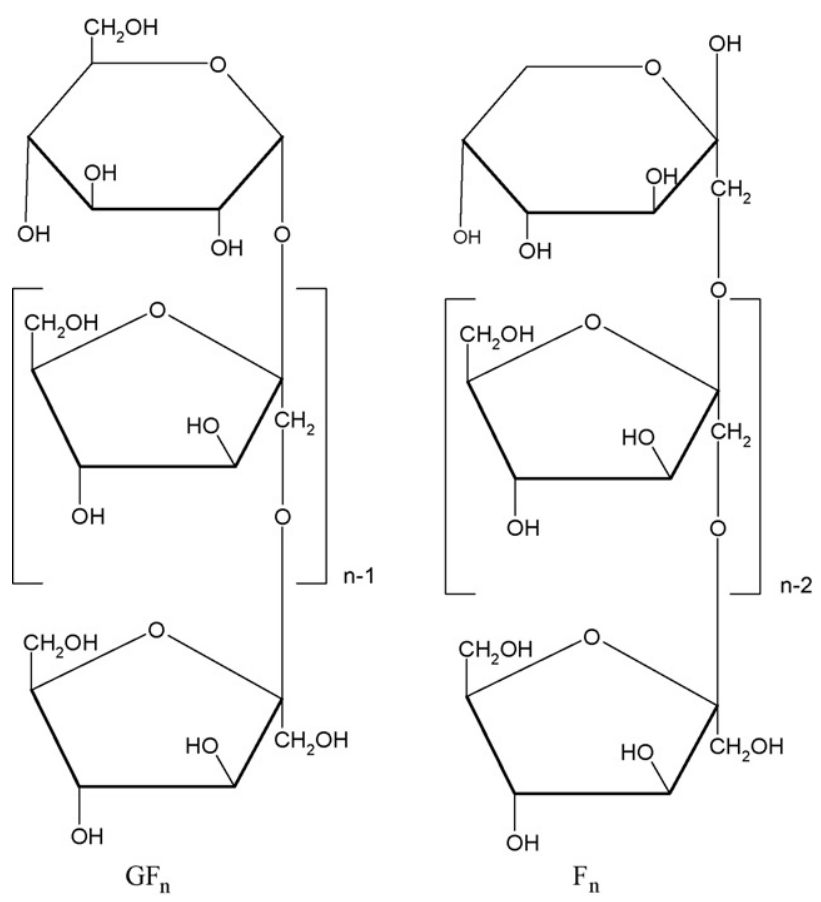

Fig. 1 - Chemical structure of $G_{n}(\alpha-D-g l u c o p y r a n o s y l-[\beta-D-$ fructofuranosyl $]_{n-1}-D$-fructofuranoside) and $F_{n}$ ( $\beta$-D-fructopyranosyl-[ $\alpha$-D-fructofuranosyl $]_{n-1}$-Dfructofuranoside) molecules. $n$ is the degree of polymerization or the number of $\beta$-D-fructofuranose units; $\mathrm{G}$ and $\mathrm{F}$ stand for glucose and fructose, respectively.

fat replacer and/or prebiotic agent [4], inulin producers have developed different commercial inulins mainly from chicory roots. A variety of fractionated inulin can be produced from native inulin (without modification after extraction) by physical, chemical or enzymatic processes, leading to products with a defined range of degree of polymerisation (DP) and specific properties [5]. For example, inulin can be partially hydrolyzed by endo-inulinase in order to produce highly soluble and sweet oligosaccharides while still retaining prebiotic properties [6-8]. This reaction leads to short oligomers as the enzyme breaks each 2-4 fructose units and so enriches the product in inulooligosaccharide ( $F_{n}$-type inulin).

Amongst the techniques used for inulin analysis, highperformance anion exchange chromatography coupled with pulsed amperometric detection (HPAEC-PAD), is the most powerful tool as its resolution power is able to separate each degree of polymerization and their isomers (distinction between $F_{n}$ and $G_{n-1}$ ). However, one of the remaining problems of HPAEC-PAD is the difficulty to predict the elution order of sugar oligomers, since in most instances, no standards are available $[9,10]$. To our knowledge, only $\mathrm{GF}_{2-4}$ are commercialized, enabling their identification in the inulin chromatogram. So, based on the assumption that the retention time of $\mathrm{GF}_{n}$ increases according to the DP, and that each successive peak represents an oligomer with an extra fructose, it is possible to identify the $\mathrm{GF}_{n}$ sequence [11]. However, the elution order of oligofructoses (partially hydrolyzed inulins) is more difficult to predict as $\mathrm{F}_{n}$ and $\mathrm{GF}_{n}$ coexist in the same chromatogram and no $F_{n}$ standards exist to identify them.

The aim of the present work was to develop a method to obtain $F_{n}$ oligomer standards and to identify them in the complex inulin chromatogram. Although partially hydrolyzed commercial inulins already contain $F_{n}$, the purification step to produce standards would be hampered by the high $\mathrm{GF}_{n}$ content, so the preference was given to an endo-inulinase hydrolysis of a high DP inulin. Indeed, whatever the DP of the initial $\mathrm{GF}_{n}$, only one molecule containing a terminal glucose is released; while the amount of $F_{n}$ oligomers increases with the length of the fructose chain (Fig. 2). In this study, globe artichoke inulin was preferred since it is well known for its high degree of polymerization [2]. The hydrolysis of this high DP inulin led to a very high $\mathrm{F}_{n}$ content with few $\mathrm{GF}_{n}$, thus limiting their interference during the $F_{n}$ purification step.

Inulin was extracted from globe artichoke, purified and hydrolyzed by endo-inulinase. $F_{n}$ oligomers standard molecules were obtained using a semi-preparative highperformance size exclusion chromatography (HPSEC). Purity of each fractionated $F_{n}$ was ascribed by HPAEC-PAD; while electrospray ionization mass spectrometry (ESI-MS) was used to determine the degree of polymerization of the purified molecule. Finally, glucose, fructose, sucrose, the $F_{n}$-purified molecules and some $\mathrm{GF}_{n}$ commercially available molecules

$$
\begin{gathered}
\mathrm{F}-\mathrm{F}-\mathrm{F}-\mathrm{F}+\mathrm{F}-\mathrm{F}+\mathrm{F}-\mathrm{F}-\mathrm{F}+\mathrm{F}-\mathrm{F}-\mathrm{F} f(\mathrm{~F})_{\mathrm{m}} \mid \mathrm{F}-\mathrm{F}-\mathrm{F}-\mathrm{F}-\mathrm{F}-\mathrm{F}-\mathrm{F}-\mathrm{F}-\mathrm{F}-\mathrm{F}-\mathrm{G} \\
\downarrow \\
\downarrow \\
\mathrm{F}-\mathrm{F}-\mathrm{G} \\
\mathrm{F}-\mathrm{F}-\mathrm{F}+\mathrm{F}-\mathrm{F} \\
+\mathrm{F}-\mathrm{F}-\mathrm{F}+\mathrm{F}-\mathrm{F}-\mathrm{F}+\mathrm{F}-\mathrm{F}-\mathrm{F} \\
\mathrm{F}-\mathrm{F}-\mathrm{F}-\mathrm{F} \\
\mathrm{F}_{\mathrm{m}}
\end{gathered}
$$

Fig. 2 - Example of the action of endo-inulinase hydrolysis on a high degree of polymerization inulin. $G$ and $F$ represent glucose and fructose, respectively. After hydrolysis by endo-inulinase, each initial $\mathrm{GF}_{n}$ yields one fructooligosaccharide and several inulooligosaccharides which increase with the number of fructose units of the initial chain; justifying the choice of globe artichoke inulin compared to other sources (i.e. chicory root). 
were used to determine the order of elution in complex HPAEC-PAD chromatograms of oligofructose commercial products.

\section{Materials and methods}

\subsection{Extraction of globe artichoke inulin}

The general strategy to extract and purify globe artichoke inulin is presented in Fig. 3. Gobe artichoke frozen fresh (Var. Petit violet, purchased from 'Compagnie bretonne de l'artichaut') were thawed and then grated into slices. Inulin was extracted from $12 \mathrm{~kg}$ of globe artichoke by $50 \mathrm{~L}$ distilled water $\left(80^{\circ} \mathrm{C}\right)$ at pH 6.8 (by $\mathrm{NaOH}$ ) in order to avoid inulin hydrolysis at $\mathrm{pH}<6$ [12]. Extracted juice was filtered on $1 \mathrm{~mm}$ and $5 \mu \mathrm{m}$ filters. Inulin was then precipitated by freezing/thawing, and the precipitate was centrifuged at $3000 \times g$ for $20 \mathrm{~min}$. The pellet ( $25 \%$ dry matter) was separated from the supernatant and was dispersed in distilled water at $95^{\circ} \mathrm{C}$ (5\% final concentration). The turbidity of the dispersion was eliminated by ultra filtration using a $10^{5} \mathrm{Da}$ cut off (hollow fibre cartridge

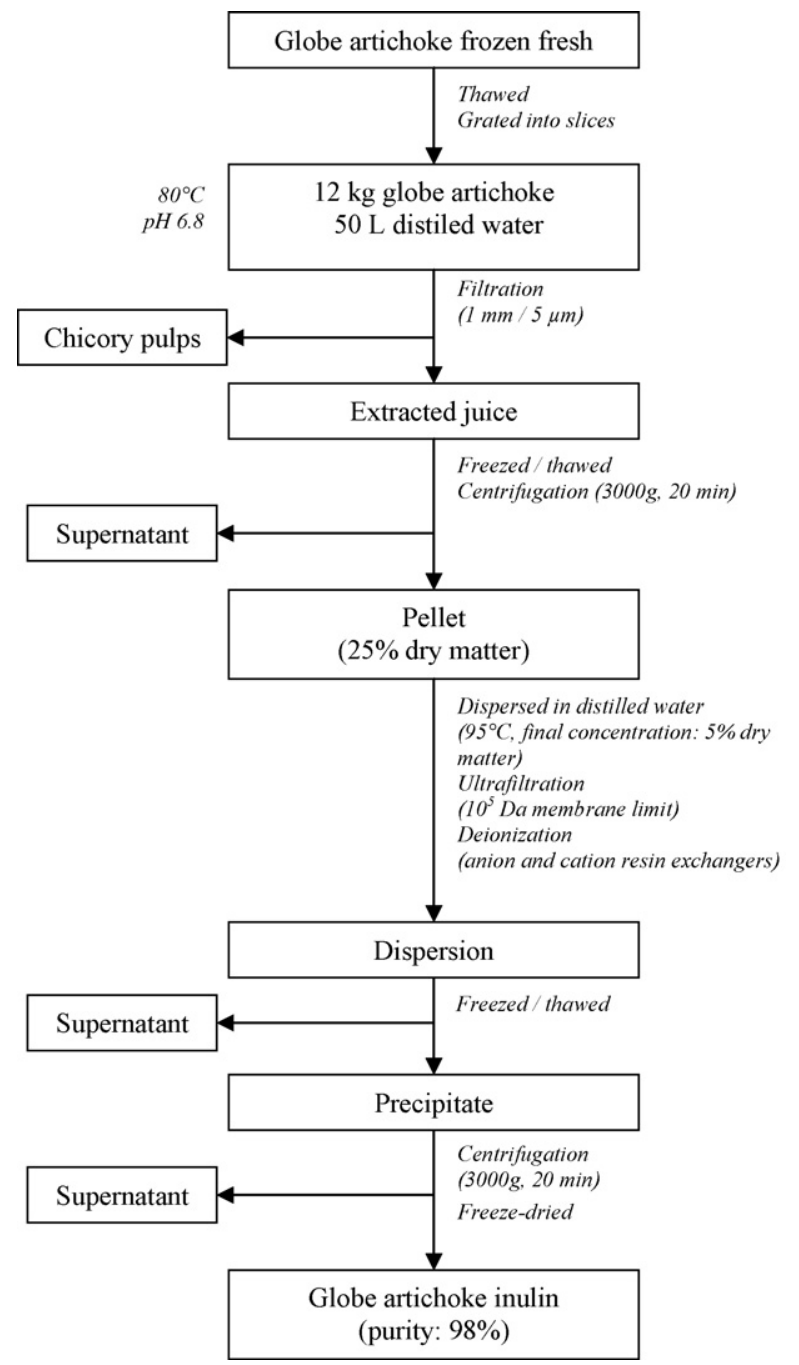

Fig. 3 - Schematic procedure of globe artichoke inulin extraction.
PM 100, Romicon). Then, the filtrate was deionised by passing through strong anionic and cationic resin exchangers. The product was again freezed/thawed and the precipitate centrifuged at $3000 \times g$ for $20 \mathrm{~min}$. The pellet was separated from the supernatant and freeze-dried. The ash content was lower than $2 \%$.

\subsection{Hydrolysis of globe artichoke inulin}

$2.5 \mathrm{~g}$ globe artichoke inulin was mixed with $50 \mathrm{~mL}$ of distilled water and two drops of $\mathrm{NaOH} 0.1 \mathrm{M}$, and heated to boiling. The $\mathrm{pH}$ was adjusted to 4.52 by $\mathrm{AcNa}(0.5 \mathrm{M})$ and $\mathrm{HCl}$ $(0.5 \mathrm{M})$ in order to be in the optimal working range of the enzyme [13]. A volume of $125 \mu \mathrm{L}$ of endo-inulinase oligofructase $30001800 \mathrm{UI} \mathrm{mL}^{-1}$ (Beldem, Belgium) was added. This mixture was hydrolyzed at $50^{\circ} \mathrm{C}$ for $24 \mathrm{~h}$ and then boiled by microwave to inactivate the enzyme. The final product of the enzymatic reaction was lyophilized.

\subsection{Characterization of globe artichoke inulin by HPAEC-PAD}

In this study, two analytical methods were developed, both exploiting the HPAEC-PAD technique on a Dionex DX500. A volume of $25 \mu \mathrm{L}$ at a concentration of $0.8 \mathrm{gL}^{-1}$ (g purified product/L of ultrapure water) was injected on a Dionex PA100 column at a flow rate of $1 \mathrm{~mL} \mathrm{~min}^{-1}$. Elution program and solvent composition for both methods are summarized in Table 1. HPAEC-PAD method 1 allowed the visualization of the extracted globe artichoke inulin chromatographic profile, but was not suitable for the distinction between $F_{n}$ and $G_{n}$. For this reason, HPAEC-PAD method 2 was set up for $F_{n} / G_{n}$ resolution (up to DP 6) and was used for the visualization of the $F_{n}$ production during hydrolysis.

\subsection{High-performance size exclusion chromatography}

High-performance size exclusion chromatography (HPSEC) was utilized to obtain each pure $F_{n}$ oligomers on a semipreparative scale. $\mathrm{F}_{2-4}$ were purified by injecting $180 \mu \mathrm{L}$ of $23.6 \%$ solution $(\mathrm{w} / \mathrm{w})$ of $24 \mathrm{~h}$ hydrolyzed globe artichoke inulin on a MCI Gel CK0 4 S column $(200 \mathrm{~mm} \times 10 \mathrm{~mm})$ using a HPLC waters coupled to a refractive index (RI) detector. Millenium32 software was used. Elution was performed by Milli-Q water $\left(85^{\circ} \mathrm{C}\right)$ at $0.4 \mathrm{~mL} \mathrm{~min}^{-1}$. Fractions were collected from the inlet of the refractometer each $0.25 \mathrm{~min}$ and analyzed by HPAECPAD method 2 each for $0.75 \mathrm{~min}$ by diluting $10 \mu \mathrm{L}$ of the collect in $1 \mathrm{~mL}$ milli-Q water, in order to demonstrate the purity of the sample. The purest fractions corresponding to a same peak (determined by HPAEC-PAD method 2) were gathered and then freeze-dried.

\subsection{Mass spectrometry}

Electrospray ionization with a quadrupole ion trap mass analyser was utilized to ascertain the degree of polymerization of the purified oligomer. In this approach, the neutral samples were ionized in electrospray, which provides a profile of intact components. Mass spectra were recorded on a Bruker Daltonics Esquire HTC ion trap mass spectrometer equipped 
Table 1 - HPAEC-PAD method 1 and method 2 elution programs

\begin{tabular}{|c|c|c|c|c|c|}
\hline & Elution time (min) & $\mathrm{A}(\%)$ & B (\%) & $\mathrm{C}(\%)$ & Comment \\
\hline \multirow{10}{*}{ HPAEC-PAD method 1} & 0 & 100 & 0 & 0 & \multirow[t]{6}{*}{ Elution } \\
\hline & 0.1 & 100 & 0 & 0 & \\
\hline & 2 & 97 & 3 & 0 & \\
\hline & 150 & 40 & 60 & 0 & \\
\hline & 150.01 & 0 & 100 & 0 & \\
\hline & 152 & 0 & 100 & 0 & \\
\hline & 152.01 & 0 & 0 & 100 & \multirow[t]{2}{*}{ Washing } \\
\hline & 155 & 0 & 0 & 100 & \\
\hline & 155.01 & 100 & 0 & 0 & Conditioning \\
\hline & 160 & 100 & 0 & 0 & \\
\hline \multirow{18}{*}{ HPAEC-PAD method 2} & 0 & 100 & 0 & 0 & \multirow[t]{14}{*}{ Elution } \\
\hline & 1.5 & 100 & 0 & 0 & \\
\hline & 2 & 99.2 & 0.8 & 0 & \\
\hline & 4 & 96.2 & 3.8 & 0 & \\
\hline & 6 & 93.7 & 6.3 & 0 & \\
\hline & 8 & 91.4 & 8.6 & 0 & \\
\hline & 10 & 89.3 & 10.7 & 0 & \\
\hline & 12 & 87.4 & 12.6 & 0 & \\
\hline & 14 & 85.7 & 14.3 & 0 & \\
\hline & 16 & 84.1 & 15.9 & 0 & \\
\hline & 18 & 82.6 & 17.4 & 0 & \\
\hline & 20 & 81.1 & 18.9 & 0 & \\
\hline & 20.01 & 0 & 100 & 0 & \\
\hline & 23 & 0 & 100 & 0 & \\
\hline & 23.01 & 0 & 0 & 100 & \multirow[t]{2}{*}{ Washing } \\
\hline & 27 & 0 & 0 & 100 & \\
\hline & 27.01 & 100 & 0 & 0 & \multirow[t]{2}{*}{ Conditioning } \\
\hline & 35 & 100 & 0 & 0 & \\
\hline
\end{tabular}

with an electrospray ionisation source at atmospheric pressure. The samples were directly infused at $100 \mu \mathrm{L} \mathrm{h}^{-1}$ from a $2 \%$ solution (w/w) of oligomer in Milli-Q water. Mass spectra in positive mode were recorded in the range of $100-1000 \mathrm{~m} / \mathrm{z}$. Bruker Daltonics Data Analysis 3.2 software was used for data acquisition and analysis.

\section{Results and discussion}

\subsection{Characterization of extracted artichoke inulin}

The chromatographic profile of extracted globe artichoke inulin was determined by HPAEC-PAD method 1 as shown in Fig. 4. In comparison with native chicory inulin, the DP profile of extracted globe artichoke inulin showed a relatively high DP content. However, this HPAEC-PAD method 1 was not adequate for the average degree of polymerization in number $\left(\mathrm{DP}_{n}\right)$ determination as the resolution between high DP was not achieved for the use of the following equation [14]:

$\mathrm{DP}_{n}=\frac{\sum_{i=1}^{\infty} n_{i} \mathrm{DP}_{i}}{\sum_{i=1}^{\infty} n_{i}}$

where $n_{i}$ is the number of moles of an oligomer with $i$ residues and $\mathrm{DP}_{\mathrm{i}}$ is the corresponding DP.

For this reason, the procedure to determine the $\mathrm{DP}_{n}$ was based on the principle of end group analysis [15], where $\mathrm{DP}_{n}$ is the value that corresponds to the total number of glucose and fructose units in a given inulin sample, divided by the total number of inulin molecules, without taking into account glucose, fructose and sucrose, which are initially present in the sample. Glucose, fructose and sucrose were quantitatively measured (using HPAEC-PAD method 2) before and after the total hydrolysis of globe artichoke inulin by Frutozyme $\mathrm{L}$ (Novozyme, Denmark), a commercial preparation of endo- and exo-inulinase from Aspergillus niger. By calculating the fructose to glucose ratio, $\mathrm{DP}_{n}$ was determined as the number of fructose units per number of glucose units plus one in the following equation:

$\mathrm{DP}_{n}=\frac{F_{\text {end }}-F_{\text {start }}}{G_{\text {end }}-G_{\text {start }}}+1$

where $F_{\text {start }}$ and $F_{\text {end }}$ are the fructose concentration before and after total hydrolysis, respectively and $G_{\text {start }}$ and $G_{\text {end }}$ are the glucose concentration before and after total hydrolysis, respectively.

An average degree of polymerisation number $\left(\mathrm{DP}_{n}\right)$ of about 80 was found for globe artichoke inulin. In comparison with other various native inulin sources, globe artichoke inulin showed the highest $\mathrm{DP}_{n}$ value [2].

The advantage of such a product was that one resulting molecule containing a terminal glucose $\left(G_{n}\right)$ was present for several $F_{n}$ oligomers produced from the globe artichoke initial $\mathrm{GF}_{n}$ after endo-inulinase hydrolysis (Fig. 2). Moreover, the globe artichoke inulin extraction method used eliminated the first seven DP, as shown in Fig. 4. This 


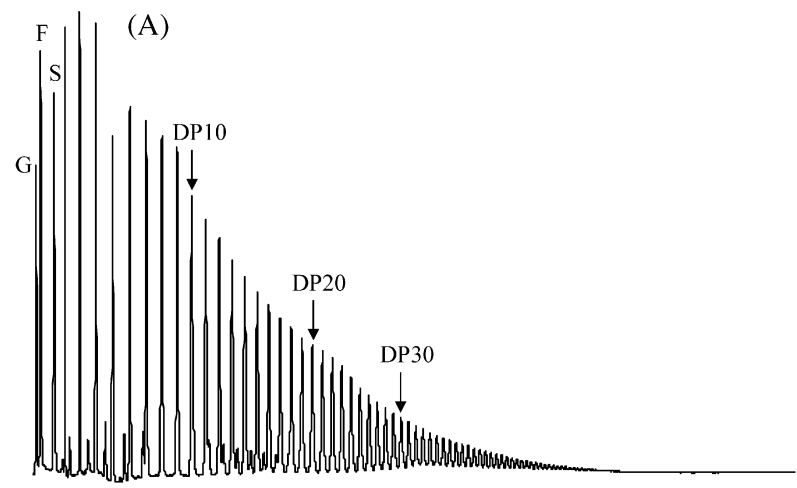

(B)

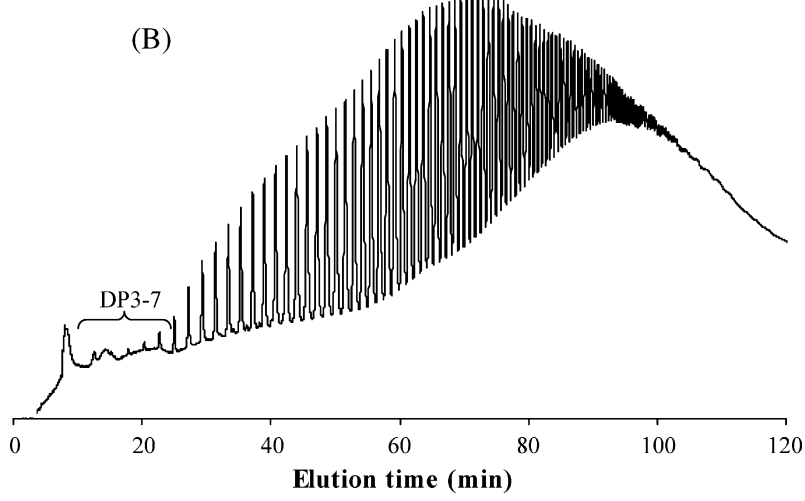

Fig. 4 - HPAEC-PAD method 1 chromatogram of inulin (A) from a commercial native chicory root sample and (B) from extracted globe artichoke. $G, F$ and $S$ represent glucose, fructose and sucrose, respectively.

way, a very high $F_{n}$ content with fewer $G_{n}$ issued from the endo-inulinase hydrolysis or from the starting material was obtained after hydrolysis, facilitating the $F_{n}$ purification step.

\subsection{Artichoke inulin hydrolysis}

The HPAEC-PAD method 1 developed in this study allowed the global visualization of the inulin profile. However, this method was not able to distinguish between $F_{n}$ and $G_{n}$. In most of the studies, the resolution between these isomers is not done. Moreover, the assignment of the chromatographic peaks of inulin with DP $>3$ was based on the generally accepted assumption that the retention time of a homologous series of inulin increased with the DP, and that each successive peak represented a fructan with a fructose more than the previous peak [11]. However, in such studies, no distinction between $F_{n}$ and $\mathrm{GF}_{n}$ were made, and a principal peak $\left(\mathrm{GF}_{n}\right)$ with a shoulder $\left(F_{n}\right)$ generally appeared.

In order to characterize more deeply the $F_{n}$ production by distinguishing them from $\mathrm{GF}_{n}$, another HPAEC-PAD method was developed in this study. This HPAEC-PAD method 2 is described in Table 1 , and has permitted the distinction between $\mathrm{F}_{n}$ and $\mathrm{GF}_{n}$ for $\mathrm{DP}<6$.

During the course of globe artichoke inulin hydrolysis by endo-inulinase, aliquots of the reaction mixture were periodically withdrawn and analyzed by HPAEC-PAD method 2. As

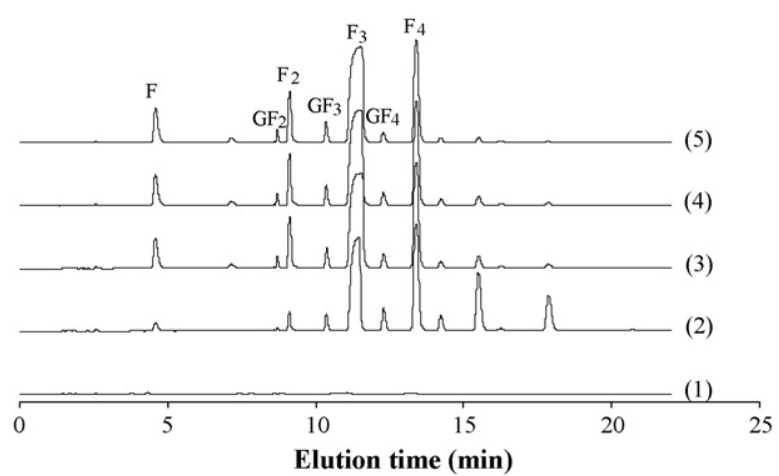

Fig. 5 - HPAEC-PAD method 2 analysis of the endo-inulinase kinetic hydrolysis of globe artichoke inulin after (1) $0 \mathrm{~h},(2) 2.5 \mathrm{~h}$, (3) $18.5 \mathrm{~h}$, (4) $20.5 \mathrm{~h}$ and (5) $24.0 \mathrm{~h}$ hydrolysis.

shown in Fig. 5, the endo-inulinase hydrolysed linear $\beta-2,1$ linked fructose polymers to $\mathrm{F}$ and $\mathrm{F}_{2-4}$. After $24 \mathrm{~h}$ hydrolysis, $\mathrm{F}_{3}$ was the major product, followed by $\mathrm{F}_{4}$. No diminution of the $F_{3}$ and $F_{4}$ content was observed after $24 \mathrm{~h}$ hydrolysis time (data not shown). This is probably due to the high purity of the endo-inulinase and thus an absence of exoinulinase in the commercial enzyme product. Moreover, Yun et al. [16] claimed that the general mode of endo-inulinase action is that the hydrolytic activity for inulin increases with the degree of polymerisation of fructosyl residues. For this reason, endo-inulinase hydrolyzed high DP inulin to produce $\mathrm{F}_{2-4}$, but could not work on small DP such as 1-kestose $\left(\mathrm{GF}_{2}\right)$ or nystose $\left(\mathrm{GF}_{3}\right)$ [16], so only a low sucrose peak was detected on HPAEC-PAD method 2 chromatogram after $24 \mathrm{~h}$ hydrolysis time (Fig. 5).

\section{3. $\quad F_{n}$ purification by high-performance size exclusion chromatography (HPSEC)}

The chromatograms obtained by HPSEC of hydrolyzed artichoke inulin revealed four peaks as shown in Fig. 6. According to the elution order, these peaks could correspond to the oligomers of interest. HPSEC provided sufficiently good separation of the extracted $F_{n}$ as some relatively pure fractions were obtained for mass spectrometry analysis. Indeed, HPAEC-PAD method 2 permitted the visualization of the four corresponding molecules (later identified as fructose, $F_{2-4}$ ).

\section{4. $F_{n}$ molecular weight determination}

The ESI positive-ion mode mass spectra of $\mathrm{F}_{2-4}$ showed their sodiated molecule $[\mathrm{M}+\mathrm{Na}]^{+}$at $\mathrm{m} / \mathrm{z} 365.1,527.1$ and 689.2, respectively (Fig. 7), ascribing the degree of polymerization of these molecules (Table 2). The molecular potassiated ion $[\mathrm{M}+\mathrm{K}]^{+}$was also detected for $\mathrm{F}_{2}$ as presented in Fig. 7a. The mass spectrum of $\mathrm{F}_{3}$ (Fig. 7b) presented the double charge $[\mathrm{M}+\mathrm{H}+\mathrm{Na}]^{++}$at $m / z=272.1$, while $[\mathrm{M}+\mathrm{H}+\mathrm{K}]^{++}$ was observed for $F_{4}$ at $m / z=353.1$. Spectrum of $F_{4}$ presented peaks at $\mathrm{m} / \mathrm{z}=527.1$ and $\mathrm{m} / \mathrm{z}=203.0$, probably resulting from the fragmentation of $\mathrm{F}_{4}$ into fructose and the asso- 
(a)

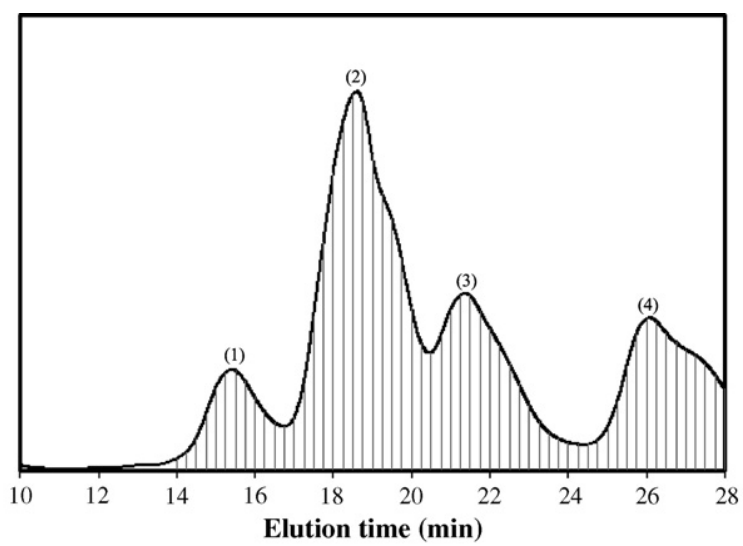

(b)

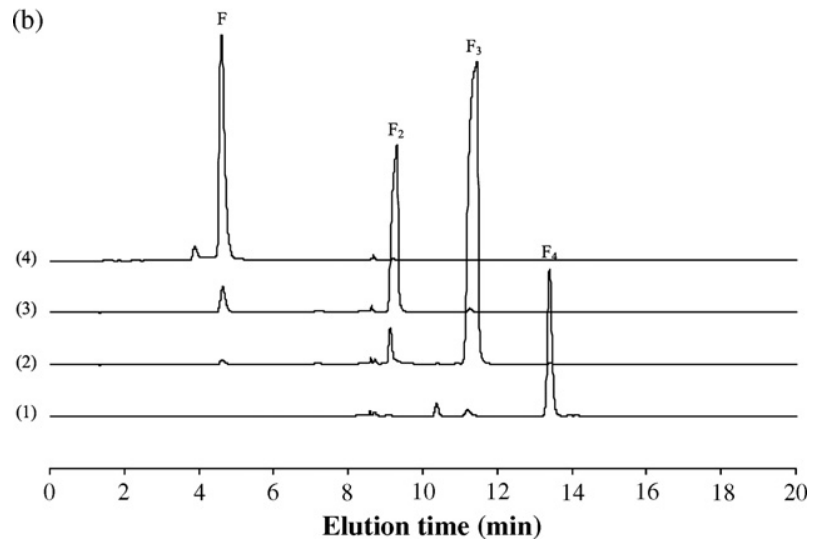

Fig. 6 - (a) High-performance size exclusion chromatography separation of hydrolyzed globe artichoke inulin on a MCI Gel CK04S column (200 mm x $10 \mathrm{~mm}$ ) using refractive index detection. Elution was performed by Milli- $Q$ water $\left(85^{\circ} \mathrm{C}\right)$ at $0.4 \mathrm{~mL} \mathrm{~min}^{-1}$. (b) HPAEC-PAD method 2 chromatograms of the collected fractions (1)-(4) obtained by HPSEC.

ciated tri-fructose, in the sodiated form (Fig. 7c). However, as the DP increased, the mass spectra became more complex due to an increase in double-charging phenomena. These kinds of results have also been reported by Campa et al. [14] who observed this phenomenon of double charge, by analyzing fragmentation of oligosaccharides in a partially acid-hydrolysed homopolysaccharide in the ESI negative mode.

Table 2 - Positive-ion electrospray ionization of the main mass fragmentation of (a) $F_{2},(b) F_{3}$ and (c) $F_{4}$

\begin{tabular}{lll} 
Oligomer type $(\mathrm{M})$ & Type of ion & $\mathrm{m} / \mathrm{z}$ \\
\hline $\mathrm{F}_{2}$ & {$[\mathrm{M}+\mathrm{Na}]^{+}$} & 365.1 \\
& {$[\mathrm{M}+\mathrm{K}]^{+}$} & 381.1 \\
$\mathrm{~F}_{3}$ & {$[\mathrm{M}+\mathrm{H}+\mathrm{Na}]^{++}$} & 272.1 \\
& {$[\mathrm{M}+\mathrm{Na}]^{+}$} & 527.1 \\
$\mathrm{~F}_{4}$ & {$[\mathrm{M}+\mathrm{H}+\mathrm{K}]^{++}$} & 353.1 \\
& {$[\mathrm{M}+\mathrm{Na}]^{+}$} & 689.2 \\
\hline
\end{tabular}
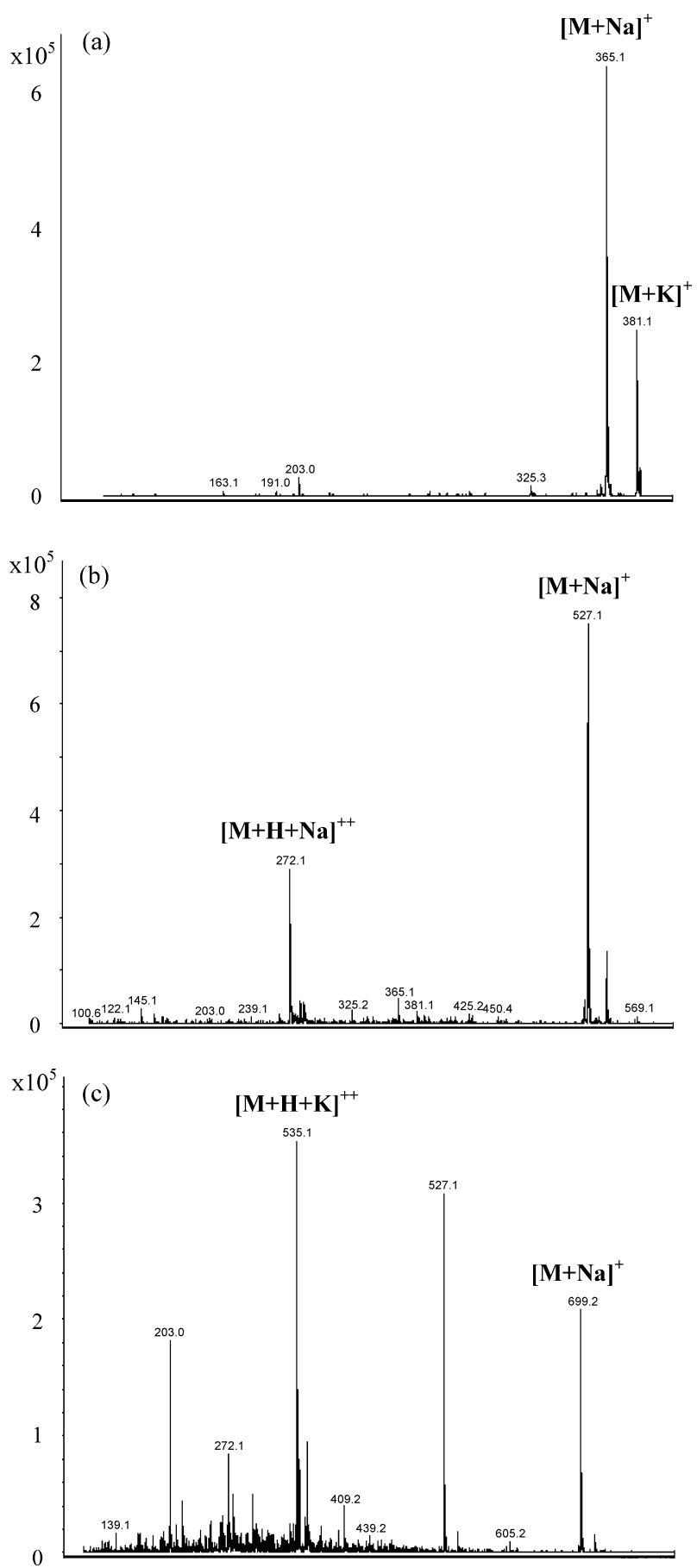

Fig. 7 - Positive-ion electrospray ionization mass spectra of (a) $F_{2}$, (b) $F_{3}$ and (c) $F_{4}$.

3.5. Elution order of $\mathrm{F}_{2-4}, \mathrm{GF}_{2-4}$ and their related component on oligofructose HPAEC-PAD chromatograms

According to Farine et al. [17], one of the remaining problems of HPAEC-PAD, is the difficulty in predicting the elution order of sugar oligomers, since in most instances, no standards are available. In our study, the main problem was to predict the elution order of $\mathrm{F}_{n}$ and $\mathrm{GF}_{n}$ in the complex oligofructose chromatogram. Usually, the assignment of the chromatographic 

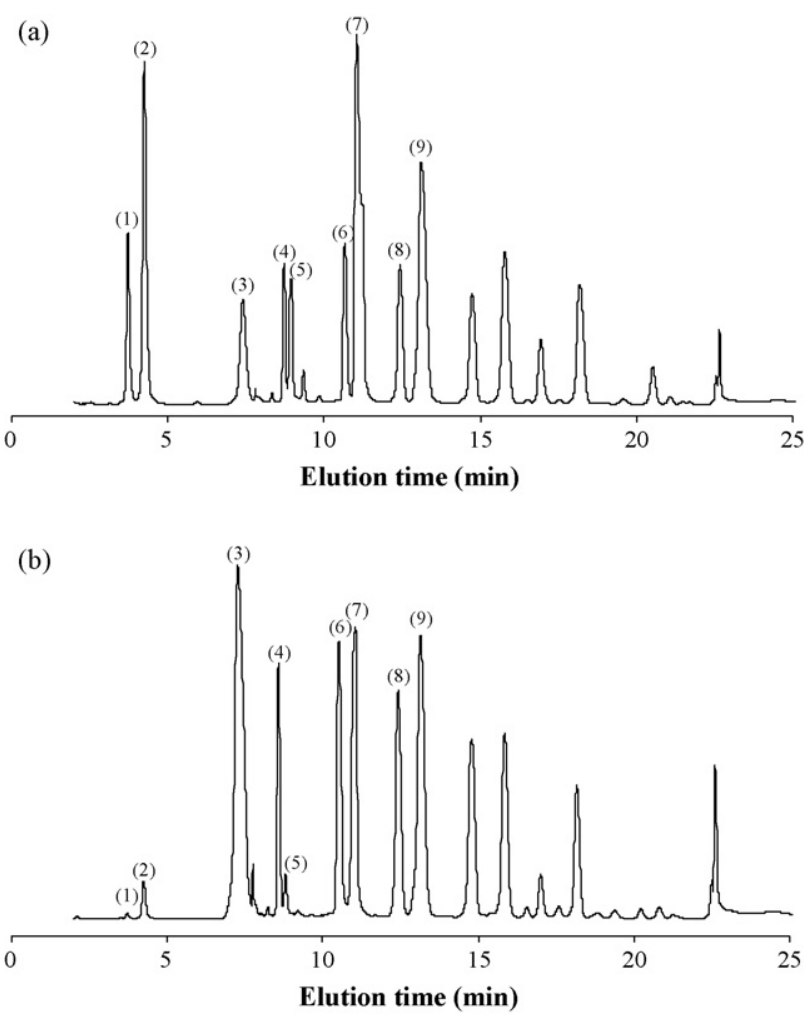

Fig. 8 - ( $a$ and $b$ ) HPAEC-PAD method 2 chromatograms of various commercial oligofructose produced from partial chicory root inulin hydrolysis. For confidentiality purposes, the generic names of these products purchased from different companies are not indicated. (1) Glucose, (2) fructose, (3) sucrose, (4) $G_{2},(5) F_{2},(6) G_{3},(7) F_{3},(8) G_{4}$ and (9) $F_{4}$. The elution order has been confirmed by spiking the oligofructose samples with the standards and purified molecules.

peaks with DP higher than three is based on the assumption that the retention time of a homologous series of carbohydrates increased as the DP increased, and that each successive peak represented a fructan with an extra fructose than the previous peak [11]. As fructose, glucose, sucrose, $\mathrm{GF}_{2-4}$ and $\mathrm{F}_{2-4}$ were now available; different commercial oligofructose samples (purchased from different companies) were separately spiked by these products in order to determine their elution order, as shown in Fig. 8. The precise values of the retention times obtained were slightly dependent on the precise concentration of eluent, but in all cases the retention times had the following sequence: glucose (G), fructose $(F)$, sucrose (GF), kestose $\left(\mathrm{GF}_{2}\right)$, inulobiose $\left(\mathrm{F}_{2}\right)$, nystose $\left(\mathrm{GF}_{3}\right), \mathrm{F}_{3}, \mathrm{GF}_{4}$ and $\mathrm{F}_{4}$. The knowledge and the accuracy of this elution order are of crucial importance because $\mathrm{F}_{n}$ and $\mathrm{GF}_{n}$ molecules do not have the same response factor in the HPAEC-PAD system [18]. This fact is important to underline because if no distinction between these molecules is made, an error in the oligofructose content of a food product can occur during quantitative analysis.

\section{Conclusion}

This work described a procedure to obtain $F_{n}$ oligomers of high purity from globe artichoke inulin hydrolysis with the aim to identify them in commercial oligofructose samples. Globe artichoke inulin was isolated, purified, and hydrolyzed by endo-inulinase. $\mathrm{F}_{2-4}$ resulting products were individually isolated by HPSEC and their degree of polymerization ascertained by ESI-MS. An adapted HPAEC-PAD method permitted the resolution between $\mathrm{GF}_{n}$ and $\mathrm{F}_{n}$, allowing the oligofructose and the globe artichoke inulin hydrolysis analysis. Finally, industrial oligofructose samples were spiked using glucose, fructose, sucrose, $\mathrm{GF}_{2-4}$ and the purified $\mathrm{F}_{n}$ oligomers, in order to determine the elution order in the complex oligofructose chromatogram. HPAEC-PAD was a powerful technique for oligofructose characterization, but the detector response of $\mathrm{GF}_{n}$ and $\mathrm{F}_{n}$ must be established in a further study in order to quantify them in food enriched in oligofructose.

\section{REFERENCES}

[1] M.B. Roberfroid, N.M. Delzenne, Annu. Rev. Nutr. 18 (1998) 117.

[2] W. Praznik, R.H.F. Beck, J. Chromatogr. 348 (1985) 187.

[3] L. De Leenheer, H. Hoebregs, Starch 5 (1994) 193.

[4] C. Blecker, J.-P. Chevalier, J.-C. Van Herck, C. Fougnies, C. Deroanne, M. Paquot, Recent Res. Dev. Agric. Food Chem. 5 (2001) 125.

[5] S.N. Ronkart, C. Deroanne, M. Paquot, C. Fougnies, J.-C. Lambrechts, C.S. Blecker, Food Biophys. 2 (2007) 83-92.

[6] J. Zhengyu, W. Jing, J. Bo, X. Xueming, Food Res. Int. 38 (2005) 301.

[7] D.H. Kim, Y.J. Choi, S.K. Song, J.W. Yun, Biotechnol. Lett. 19 (1997) 369.

[8] E. Menne, N. Guggenbuhl, M. Roberfroid, J. Nutr. 130 (2000) 1197.

[9] S. Ronkart, C. Blecker, C. Fougnies, J.-C. Van Herck, J. Wouters, M. Paquot, Carbohydr. Polym. 63 (2006) 210.

[10] S.N. Ronkart, M. Paquot, C. Fougnies, C. Deroanne, J.-C. Van Herck, C. Blecker, Talanta 70 (2006) 1006.

[11] C. Corradini, F. Bianchi, D. Matteuzzi, A. Amoreti, M. Rossi, S. Zanoni, J. Chromatogr. A 1054 (2004) 165.

[12] C. Blecker, C. Fougnies, J.-C. Van Herck, J.-P. Chevalier, M. Paquot, J. Agric. Food Chem. 50 (2002) 1602.

[13] B.V. McCleary, A. Murphy, D.C. Mugford, J. AOAC Int. 83 (2000) 356.

[14] C. Campa, A. Oust, G. Skjåk-Braek, B.S. Paulsen, S. Paoletti, B.E. Christensen, S. Balance, J. Chromatogr. A 1026 (2004) 271.

[15] D. López-Molina, M.D. Navarro-Martínez, F.R. Melgarejo, A.N.P. Hiner, S. Chazarra, J.N. Rodríguez-López, Phytochemistry 66 (2005) 1476.

[16] J.W. Yun, D.H. Kim, B.W. Kim, S.K. Song, Biotechnol. Lett. 19 (1997) 553.

[17] S. Farine, C. Versluis, P.J. Bonnici, A. Heck, J.L. Peschet, A. Puigserver, A. Biagini, J. Chromatogr. A 929 (2001) 299.

[18] S.L. Kang, Y.J. Chang, K.Y. Kim, S.I. Kim, Agric. Chem. Biotechnol. 42 (1999) 166. 